\title{
VIEWPOINT
}

\section{From anecdote to formal evaluation: Reflections from more than two decades on the local food research trail at USDA}

\author{
Debra Tropp * \\ Debra Tropp Consulting
}

Submitted May 4, 2019 / Accepted May 5, 2019 / Published online August 13, 2019 / Corrected version September 30 , 2019

Citation: Tropp, D. (2019). From anecdote to formal evaluation: Reflections from more than two decades on the local food research trail at USDA. Journal of Agriculture, Food Systems, and Community Development, 9(1), 13-30. https://doi.org/10.5304/jafscd.2019.091.044

Copyright (C) 2019 by the Author. Published by the Lyson Center for Civic Agriculture and Food Systems. Open access under CC-BY license.

\section{Introduction}

In the waning days of my career at the U.S.

Department of Agriculture (USDA), the editors of this journal encouraged me to share some reflections about the evolution of local food research and data collection during the past two decades, and I am deeply appreciative for the opportunity. It has been my great fortune to have witnessed the extraordinary transformation of the local food sector firsthand since the mid-1990s. What started out as a minor assignment to oversee a single-and eventually unsuccessful-cooperative research agreement on school food procurement with the Georgia Department of Agriculture in 1995 ended up piquing my interest about the opportunity for growth in local food sales within institutional and commercial food service, as well as retail channels. This subject has remained the primary focus of my professional life and a subject of vast curiosity for me ever since. For someone like me, who has been

Debra Tropp, Principal, Debra Tropp Consulting, Kensington, MD. Debra Tropp spent more than 26 years at the USDA Agricultural Marketing Service's Transportation and Marketing Program, retiring at the end of January 2019. During her tenure at AMS, Ms. Tropp played a key role in developing and overseeing the development of research projects and guidance material (aimed at small and midsized producers) that shared practical insights about market requirements, preferences, and economic benefits associated with changes in operational and marketing practices within the food supply chain. Over the course of her career, she served in a variety of roles of increasing responsibility, including agricultural economist, interim staff officer for the Federal-State Marketing Improvement Program (a competitive grant program that supports market research projects), team leader and chief of the Farmers Market and Direct Farm Marketing Research Branch, and finally, deputy director of AMS's Marketing Service Program, which focuses on local and regional food system research and development. Most recently, she served as the primary editor for the AMS-sponsored report, The Economics of Local Food Systems: A Toolkit to Guide Community Discussions, Assessments and Choices (March 2016), and as a member of the task force that framed and produced the Federal Reserve and USDA book, Harvesting Opportunity: The Power of Regional Food System Investments to Transform Communities (August 2017). She can be reached by telephone at +1-301-949-4482 or by email to Debra.Tropp@gmail.com. 
immersed in the world of local food systems for more than 20 years, it is staggering-and gratifying-to consider both the profound changes in research and data availability that have occurred over the course of my career, and the multiplicity of ways that relevant evidence and data can now be employed to guide business and community development through local food system expansion. My intent in this article is to briefly examine the chronological history of local food research at USDA as I experienced it "in the trenches," and observe the combination of Congressional mandate, political influence, personal curiosity, and, sometimes, pure serendipity that permitted this body of work to emerge.

It should be noted that my personal experiences and observations are strongly shaped by my career-long affiliation with USDA's Agricultural Marketing Service (AMS), an agency that has been mandated by Congress since 1946 to promote efficiency in the U.S. food marketing system and help producers attain a greater share of consumer food expenditures. ${ }^{1}$ Therefore, while I acknowledge the many health, equity, and environmental benefits that may be achieved through local food system development and expansion, I am deliberately confining the bulk of my remarks to the economic contributions of local food systems from a producer standpoint, and USDA's important role in bringing such data and information to light.

\section{The Early Days: USDA and Local Food, 1995-2000}

During the first few years that I was engaged in studying local procurement trends, USDA regarded the local food sector as a niche contributor to the U.S. food economy, and one that was primarily of interest to small-scale farmers and their customers. Consumers of local food were largely perceived as core patrons of farmers market and community supported agriculture (CSA) who were partially motivated by emerging research pointing to the environmental superiority of purchasing food closer to its place of origin (Pirog, Van Pelt, Enshayan, \& Cook, 2001), and who relied on direct marketing outlets as sources of high-quality organic or sustainably produced fresh foods at a time when such foods were not always available from mainstream retail outlets (Organic Trade Association \& GRO Organic Core Committee, 2015). The minimal importance accorded to the economic contribution of local food to the U.S. food economy was exemplified by the fact that, even as late as 2007 , the Census of Agriculture only included two questions about local food sales - both strictly pertaining to direct-to-consumer marketing channels. It should be noted that each of these questions was worded in a way that circumscribed the ability of researchers to fully gauge the economic significance of these marketing outlets. One of the survey questions asked producers to report the value of agricultural products "sold directly to individuals for human consumption," including at direct-toconsumer retail outlets such as "roadside stands, farmers markets and pick your own, etc." (explicitly excluding such high-value processed foods such as "jams, sausages and hams," and non-edible products such as cut flowers and nursery plants (USDA NASS, 2007, p. 81). The other question asked producers to report whether they marketed any of their agricultural products through a CSA "arrangement," which yielded an unexpectedly high number of affirmative responses (over 12,000) but failed to yield clear understanding about the actual role played by CSAs in moving agricultural products from farmers to consumers (Robyn Van En Center Staff, 2009).

In line with the prevailing assumption at the time that direct-to-consumer and local food sales remained a niche market with limited economic importance, during the late 1990s and early 2000s, the handful of career civil servants at USDA who worked on local food systems typically focused on a single aspect of local food marketing (primarily direct-to-consumer transactions) and on providing technical assistance and capacity-building services

\footnotetext{
${ }^{1}$ Agricultural Marketing Act of 1946, Sec. 203. 7 U.S.C. 1622. The original text reads: "to foster and assist in the development and establishment of more efficient marketing methods... for the purpose of bringing about more efficient and orderly marketing, and reducing the price spread between the producer and the consumer." See

https://www.ams.usda.gov/sites/default/files/media/Agricultural Marketing Act Of 1946\%5B1\%5D.pdf
} 
rather than data collection and analysis. These USDA civil servants operated almost entirely within separate organizational silos and rarely engaged in interagency partnerships or coordination unless it was directly mandated by political appointees (as was the case with early farm-toschool programming at USDA during the Clinton Administration). By and large, dedicated funding for local food systems activities did not exist, although cooperative research and grant authorities were often employed to carry out local food research or demonstration projects to the extent that such activities were eligible for support.

Much of the existing local food work at USDA at the time was concentrated at Agricultural Marketing Service (AMS), which was assigned the primary responsibility of carrying out the unfunded mandates outlined in the 1976 Farmer to Consumer Direct Marketing Act. The act directs the Secretary of Agriculture to "promote, through appropriate means and on an economically sustainable basis, the development and expansion of direct marketing of agricultural commodities from farmers to consumers" (emphasis added; Public Law 94-463, 94th Congress, H.R. 10339, "Purpose”). To accomplish this objective, USDA was instructed to "initiate and coordinate a program designed to facilitate direct marketing ... for the mutual benefit of consumers and farmers" (Public Law 94-463, 94th Congress, H.R. 10339, "Purpose"). In the first several years following the enactment of the act, members of what was then known as the AMS Wholesale Market Development program attempted to fulfill this Congressional request largely by offering its existing services in site assessment and facility design to farmers market clients and their supporters. By the time I arrived at AMS in the summer of 1992, the USDA was also beginning to develop its internal capacity in market research and marketing-related technical assistance, hiring several employees to support new initiatives in direct-to-consumer market research and information sharing. Among the new initiatives launched in the mid-1990s was the initial publication (in hard copy) of the National Farmers Market
Directory, the introduction of a pilot farmers market at USDA headquarters in Washington, D.C., both in 1994, and the temporary launch of a public-facing periodic newsletter aimed at letting practitioners in the reemerging farmers market and direct-to-consumer sector learn about the available market information and resources in the preInternet era. Much of this work was initiated rather informally, relying heavily on existing USDA relationships with state government and nonprofit organization personnel to compile the most reliable national list of active farmers markets available, as well as information about relevant training and resources. Given the comparatively large share of younger businesses in the reemerging U.S. farmers market industry at the time, ${ }^{2}$ it is not surprising that AMS focused its attention on offering technical assistance services for start-up markets and baseline research on market structure and practice.

\section{Farm-to-School Pilot Projects Spark an Early AMS Embrace of a Broader Local Food Research Agenda}

One of the most important influences on the development of local food research within the USDA was AMS's support of a couple of very early farm-to-school pilot projects in Southeastern states. These included one project that eventually became a nationally renowned farm-to-school marketing success story: the revival of the New North Florida Cooperative in Marianna, Florida. A chance meeting between AMS Associate Administrator (and former University of Florida professor) Kenneth Clayton and Glyen Holmes, a Floridabased outreach coordinator for the Natural Resources Conservation Service, led AMS to support a cooperative research agreement with the New North Florida Cooperative (NNFC) in 1996. This agreement aimed to explore market opportunities in school food service for a vegetable cooperative composed of small-scale African American farmers. Project partners included Holmes, J'Amy Peterson of the Gadsden County (Florida) School District, and Vonda Richardson, extension specialist at Florida A\&M University. After a few false

\footnotetext{
${ }^{2}$ National surveys of farmers market managers conducted by AMS economists in 2000 and 2005 indicated that nearly 30 percent of all survey respondents operated markets that had been in business five years or fewer.
} 
starts, the cooperative found success in selling chopped, bagged collard greens to the school food service program, whose staff appreciated receiving fresh, culturally appropriate product that did not require further processing and could easily be included in school menus. By 2000, Holmes proved to be so successful in selling the cooperative's collard green product to school systems in the Southeast that he left his position at USDA to focus his energy entirely on working with the NNFC.

While it is unlikely that support for local food markets per se was the impetus behind AMS's support of this early farm-to-school project-a combination of White House emphasis on improving school food quality, AMS's historic interest and involvement in food procurement, and the USDA's rising focus on small farm and minority farmers' access to resources probably explain the rationale ${ }^{3}$ - the engagement of AMS marketing personnel in these early farm-to-school marketing projects had significant and long-lasting ripple effects. One such effect was encouraging eligible state agencies and land-grant institutions interested in exploring farm-to-school and other direct-toconsumer marketing prospects to consider applying for funds from AMS's single grant program that existed at the time, the Federal-State Marketing Improvement Program (FSMIP), which had a very broad scope of eligible market research activities. ${ }^{4}$ As a result, FSMIP became responsible for funding a number of early local food studies and demonstration projects before 2001, including:

- Massachusetts: US\$20,250 to assess consumer demand for locally produced foods and specialty products through development of an indoor farmers market in Boston.

- New Mexico: US\$27,000 to the New Mexico Department of Agriculture to conduct a farm-to-school pilot project involving three public schools and a newly formed cooperative of small-scale Hispanic farmers.

- Oklahoma: US\$80,000 to examine marketing practices at current and former farmers markets in Oklahoma and evaluate the economic and non-economic factors that appeared to impede or contribute to the financial success of farmers market operations.

- Pennsylvania: US\$60,750 to the Pennsylvania Department of Agriculture, in cooperation with the Center City Proprietors Foundation, to assist successful small-scale food processors in developing marketing strategies for moving their products into local retail channels.

Furthermore, because of our prior engagement with farm-to-school marketing issues, a few of us AMS employees were eventually deployed as departmental-level points of contact for questions and briefings about farm-to-school marketing and local food marketing prospects in general. In my particular case, my initial involvement with a pilot farm-to-school marketing project led to my being assigned to a departmental-wide farm-to-school task force in 1999 and my involvement in organizing the first-ever USDA farm-to-school training workshop in Georgetown, Kentucky, in 2000, in partnership with representatives from the Kentucky Department of Agriculture, University of Kentucky Extension, and members of the Food and Nutrition Service (FNS) public affairs team. I later served as primary author of the proceedings

\footnotetext{
${ }^{3}$ It is useful to note that 1996 timing of the cooperative research agreement with NNFC coincided with an important new USDAwide initiative related to school food procurement. In August 1995, an agreement was designed by administrators of the USDA Food and Nutrition Service (FNS), AMS, and the Department of Defense's (DoD) Defense Personnel Support Center to take advantage of DoD's buying power and logistical capacity in supplying produce to military bases by using the same mechanisms to provide more fresh fruit and vegetable products to schools. The report "Small Farms/School Meals Town Hall Meetings," issued by FNS in 2000, makes the connection between the DoD partnership and farm-to-school programs explicit. See https:// fns-prod.azureedge.net/sites/default/ files/small.pdf

${ }^{4}$ The other existing USDA funding stream that was used for local-oriented marketing projects at the time was the NIFA Community Food Security grant program, established in 1996. Unlike FSMIP, however, eligible projects were required to meet the needs of lowincome people by increasing their access to fresher, more nutritious food supplies.
} 
document developed from that workshop, which was published by AMS in December 2000 and set the stage for my lifelong professional interest in helping producers use local origin as a strategy for successful differentiation in the marketplace (Tropp \& Olowolayemo, 2000).

\section{Maturation of USDA Local Food Marketing Research, 2000-2007}

During this time, AMS Marketing Services increased its involvement with capturing baseline farmers market data and providing direction about direct-to-consumer marketing research and technical assistance needs in partnership with industry representatives, while initiating preliminary research on wholesale buyer interests in procuring local food. Among the major developments that occurred during this time were:

- An apparent rapid growth in farmers markets, as indicated by voluntary submissions of listings to the National Farmers Market Directory ${ }^{5}$ (Figure 1);

- Growing interest in the impact of these market establishments on local business development and community quality of life;

- The initiation of national surveys of the farmers market industry;

- The first Congressional authorization of funding for a grant program specifically dedicated to the development and expansion of farmers markets (the Farmers Market Promotion Program [FMPP]);

- Formal efforts by AMS to create a listening forum for representatives of the emerging farmers market community that would guide future program direction; and

- AMS's initial leap into research on local food procurement by commercial food service.

Figure 1. USDA National Count of National Farmers Market Directory Listings, 1994-2019

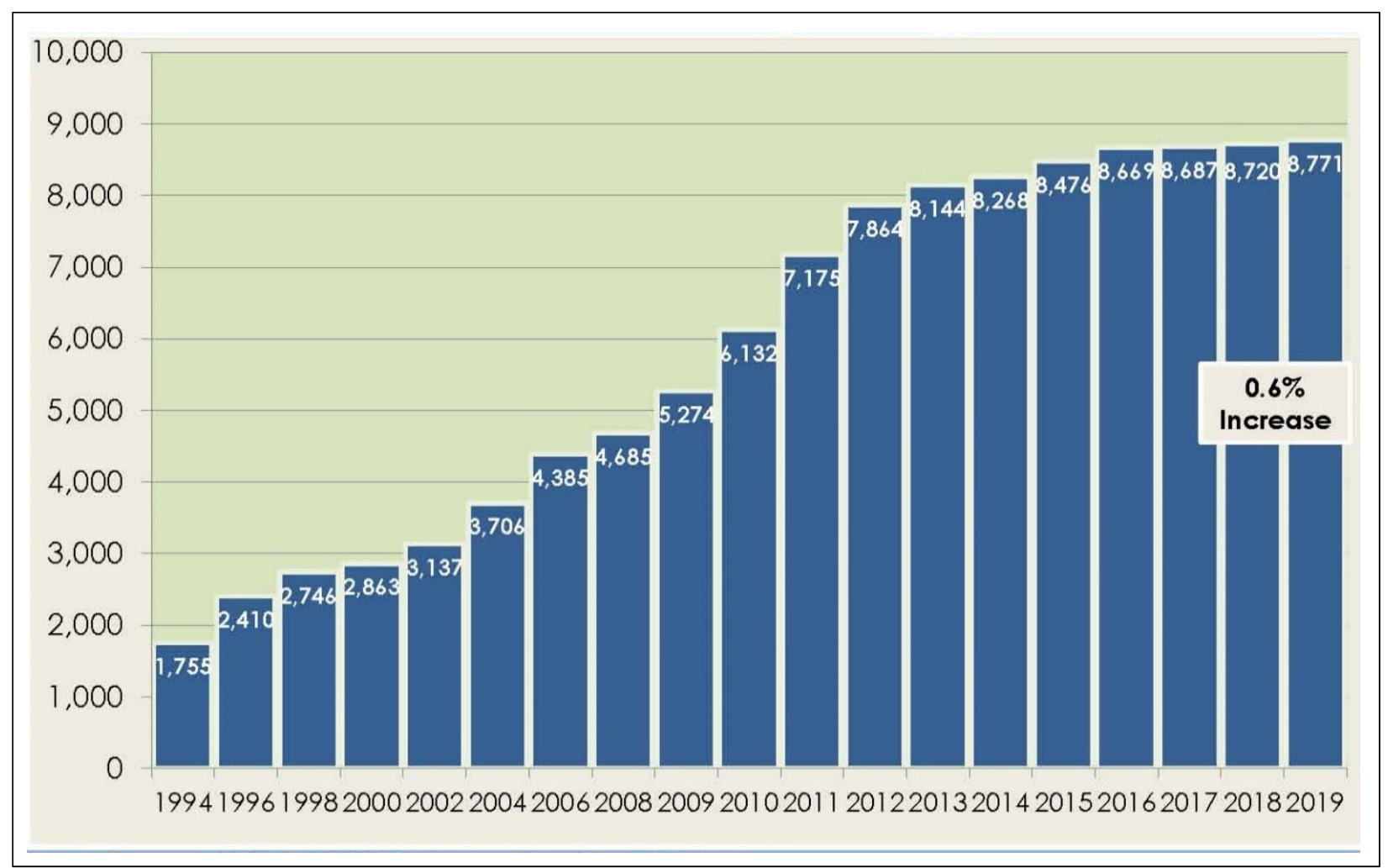

Source: U.S. Department of Agriculture, Agricultural Marketing Service, Marketing Services Division (n.d.).

${ }^{5}$ https://www.ams.usda.gov/local-food-directories/farmersmarkets 
As the numbers of farmers markets reported to USDA began to rise steeply-more than doubling between 1996 and 2006 (Figure 1)_AMS experienced an upsurge of interest from state and local governments and community planners about the role of farmers markets in stimulating local economic activity. Agency personnel responded to the growing number of inquiries in a few different ways. To obtain additional insight about the state and economic contribution of the farmers market industry, AMS hired a former state USDA National Agricultural Statistics Service (NASS) statistician to carry out its first national survey of farmers markets activities during the 2000 market year to establish a baseline profile of the sector (Ragland \& Tropp, 2009). This was followed up by a national survey of farmers market managers in about the 2005 market year by another AMS staff economist (Payne, 2002).

Accentuating AMS's interest in providing research and technical assistance services to farmer market managers, planners, and vendors was the final Congressional decision to appropriate funding for the FMPP at an initial funding level of US\$1 million per year, four years after its original enactment in the 2002 farm bill. The purpose of the FMPP program, then and now, is to competitively award grants that help increase consumption of and access to locally produced agricultural products and develop new market opportunities for farm and ranch operations participating in direct farmer-to-consumer marketing outlets (e.g., farmers markets, CSAs, roadside stands).

Facing greater public scrutiny of USDA resources targeted toward farmers market growth and expansion in the wake of this funding authorization, the AMS associate administrator at the time, Dr. Kenneth Clayton, directed the Marketing Services program in 2007 to organize a national summit for key representatives of the U.S. farmers market sector to solicit direct feedback from industry members about their core priorities and use this input to guide future program direction and resource allocation. Seventy-five individuals from across the nation attended this gathering, held in Baltimore in March 2007, representing 31 states and the District of Columbia, and a diverse array of connections to the farmers market industry (Figure 2).

To develop a national consensus about farmers market priorities, the summit was intentionally designed to promote a high level of attendee participation and interaction. Attendees worked in small assigned teams, representing diverse industry perspectives, to identify the priority needs of the farmers market sector and discuss how available resources could be brought to bear to realize desired outcomes. From a research perspective, the proceedings document assembled from highlights of discussions at the USDA National Farmers Market Summit, released in March 2008 (Tropp \& Barham, 2008), represented one of the first, if not the first, "roadmap" for direct-marketing research priorities tacitly endorsed by USDA. In that capacity, they provided broad-based direction to industry practitioners and market observers about potentially fruitful directions for research activity.
Figure 2. Stakeholder Affiliations at USDA National Farmers Market Summit, March 2007

\begin{tabular}{lc}
\hline Farmers Market Representatives & \\
\hline State Farmers Market Associations & 13 \\
Farmers Market Managers and Farmers & 12 \\
Subtotal & $\mathbf{2 5}$ \\
\hline Community Partners & 6 \\
\hline Local Nongovernmental Organizations (NGOs) & 7 \\
State Departments of Agriculture & 6 \\
University and Extension & 7 \\
Departments of Community Development, City Planning, Health & $\mathbf{2 6}$ \\
Subtotal & \\
\hline National Resource Providers & 13 \\
\hline Federal Agencies & 9 \\
National NGOs & 2 \\
Private Foundations & $\mathbf{2 4}$ \\
\hline Subtotal & $\mathbf{7 5}$ \\
\hline Total Participants & \\
\hline
\end{tabular}


In addition to setting the foundation and direction for much of the subsequent work at USDA on direct-to-consumer marketing channels, AMS Marketing Services was also responsible for initiating some of the USDA's earliest work on intermediated sales of local food to wholesale buyers. Through our early immersion in farm-toschool marketing issues, our program became acutely aware of the barriers and constraints facing smaller-scale producers who wanted access to wholesale market channels - and the potential financial benefits awaiting producers who could make that transition. We were also similarly aware of the limited revenue potential offered by many direct-to-consumer farm marketing outlets, as indicated by both anecdotal evidence and our early national surveys of farmers market managers.

Consequently, as I moved into management, I actively sought ways to integrate business-tobusiness services into our marketing program portfolio. The first opportunity arose when I served as acting staff officer for AMS's FederalState Marketing Improvement Program for approximately eight months in 2000-2001, and stumbled across a FSMIP-funded study that correlated food service market share and fresh meat sales to the financial profitability of meat processing firms in Texas (Siebert, Nayga, \& Thelen, 2000). Intrigued by the findings, I successfully pitched a follow-up research idea to the authors of this study, which led to our collaboration and AMS's publication of Expanding Commercial Food Service Sales by Small Meat Processing Firms (Tropp, Siebert, Nayga, Thelen, \& Kim, 2004), which explored the motivations among restaurant chefs and food service staff to purchase meat products close to the point of origin, as well as some of the logistical, marketing, and perceptual barriers that prevented more local transactions from occurring. The revelations that emerged from this study eventually paved the way toward AMS's involvement in research on identity preservation in the food supply chain, and toward interest in exploring how load consolidation and aggregation could be employed to yield greater efficiency and market access for local food suppliers-issues discussed further in later sections of this article.

\section{Local Food Enters the U.S. Cultural Mainstream, 2008-2013}

During 2008 to 2013, the volume of publicly available information and data on local food systems expanded substantially, reflecting a confluence of market demand factors, political will, and programmatic changes at the federal level that reinvigorated formal support for this sector of the agricultural economy. Some key markers of how deeply local food issues had permeated mainstream U.S. culture by 2008 are illustrated by the following examples:

- Michael Pollan's The Omnivore's Dilemma: A Natural History of Four Meals (published in 2006) remained on the New York Times best seller list for more than two years.

- The March 12, 2007, cover of Time magazine featured the slogan "Forget Organic, Eat Local."

- "Locavore" was designated the word of the year in late 2007 by the Oxford University Press.

- The consulting firm Packaged Facts estimated that local food demand in the U.S. reached US $\$ 5$ billion per year in 2008 .

- The number one "hot" trend among restaurant chefs at the beginning of 2009 was identified as locally sourced produce.

In the face of growing public awareness of and interest in local food system development, Congress substantially increased the amount of targeted funding available for direct-to-consumer marketing activities in the 2008 farm bill, lifting the initial authorization of funding for the Farmers Market Promotion Program from US $\$ 1$ million of discretionary funding annually to US $\$ 33$ million in mandatory funding over five years. This dramatic infusion of funding within a short time periodmoving from US $\$ 3$ million annually in 2008 to US $\$ 10$ million annually by 2011 - greatly heightened the capacity of USDA to act in service of the local food and direct farm marketing sectors.

At the same time, AMS market research analysts were beginning to tell a compelling story about the economic potential offered by local food system expansion: 
- Evidence from AMS's 2006 National Survey of Farmers Market Managers suggested that U.S. farmers markets conservatively accounted for US $\$ 1$ billion in annual sales revenue (Ragland \& Tropp, 2009).

- Excerpts of 2007 Agriculture Census data compiled by AMS researchers in 2009 revealed that the pace of growth for directto-consumer sales of agricultural products far exceeded the pace of growth for agricultural sales in general (Diamond \& Soto, 2009).

Meanwhile, AMS Marketing Services continued to explore identity preservation in food supply chains as a strategy for moving product beyond commodified markets. An assignment from USDA leadership to work in partnership with the Upper Great Plains Institute at North Dakota State University on identity-preservation issues for grain shipments led the program to develop a series of linked "supply chain basics" modules aimed at helping small and midsized agricultural producers and processors understand the logistical, inventory management, and market requirements associated with differentiated agricultural marketing practices. Titles in the series include:

- Technology: How Much, How Soon? (July 2007) ${ }^{6}$

- Niche Agricultural Marketing: The Logistics (September 2007) ${ }^{7}$

- Supply Chain Basics: Tracking Trucks With GPS (January 2008) ${ }^{8}$

- The Dynamics of Change in the U.S. Food Marketing Environment (July 2008) ${ }^{9}$

During the 2008 fiscal year, Marketing Services partnered with the California-based nonprofit Roots of Change and several early adopters in local food marketing to carry out the West Coast Direct Marketing Summit ${ }^{10}$ in June 2009, the first USDAsponsored conference that specifically identified and addressed distribution and infrastructural barriers to the movement of local food, drawing AMS further into explorations of scale-appropriate aggregation as a market-access solution.

Around this time, the new Obama Administration prioritized a focus on local and regional food systems, in which these were eventually regarded as one of four central "pillars" of agriculture and rural economic development at the USDA (USDA Office of Communications, n.d.). The primary vehicle for this focus was the establishment in May 2009 of the departmentwide Know Your Farmer, Know Your Food (KYF2) initiative by then Deputy Secretary Kathleen Merrigan, who was well known as a champion of small-scale and sustainable agriculture from her many years of affiliation with federal regulation of organic agriculture. ${ }^{11}$ Coordinated by a rotating internal leadership team composed of both political appointees and career employees, the KYF2 task force, presided over by the deputy secretary, held meetings of the entire task force membership every two weeks to foster routine information exchange across organizational silos, identify programmatic needs and bottlenecks, and develop creative solutions that would both align with regulatory and policy requirements and increase local and regional food system practitioners' access to federal resources. In addition, several KYF2 subcommittees of specialists from across USDA met regularly to address critical challenges and bottlenecks related to the themes of program awareness and access, data gathering and gap analysis, local meat processing, and aggregation and distribution. A centralized landing page ${ }^{12}$ was created to provide the public with an overview of USDA's local and regional food work in seven

\footnotetext{
${ }^{6}$ See the report at https://www.ams.usda.gov/sites/default/files/media/SupplyChain'Technology.pdf

${ }^{7}$ See the report at https://www.ams.usda.gov/sites/default/files/media/SupplyChainNicheMarketing.pdf

${ }^{8}$ See the report at http://dx.doi.org/10.9752/MS032.01-2008

${ }_{9}$ See the report at https://www.ams.usda.gov/sites/default/files/media/SupplyChainDynamicsOfChange.pdf

${ }^{10}$ See more about the summit at https://civileats.com/2009/07/10/roots-of-change-breaks-ground-with-sustainable-food-summit/

${ }^{11}$ Prior to Dr. Merrigan's appointment at USDA Deputy Secretary, she had served as AMS administrator under the Clinton Administration, where she played a key role in overseeing the promulgation of the federal rule that created the USDA National Organic Program. She also helped write the original 1990 Organic Food Production Act as a member of Senator Leahy's staff. 12 https://www.usda.gov/sites/default/files/documents/KYFCompass.pdf
} 
thematic sections, which included links to related resources and case study illustrations of relevant USDA-funded projects.

As might have been expected, the creation of the KYF2 task force and the repositioning of local food issues as key priority issues for USDA leadership led to a profusion of new data gathering and research activities within the Department. These included:

- Development and release of two ERS reports on local/regional food systems in spring 2010, Comparing the Structure, Size, and Performance of Local and Mainstream Food Supply Chains ${ }^{13}$ and Local Food Systems: Concepts, Impacts, and Issues ${ }^{14}$;

- Inclusion of a question regarding locally branded food sales to institutions in the 2011 ERS Agricultural Resource Management Survey (ARMS);

- Inclusion of a new survey question in the 2012 Census of Agriculture that, for the first time, addressed direct sales of fresh food by farmers to wholesale buyers (e.g., retailers, restaurants, food service institutions), which allowed for greater precision in analyzing the nature of local food transactions;

- A redesign of the ARMS sample design procedure in 2013 that attempted to boost response rates from small and medium-size operators (and thereby capture a greater number of farms involved in local/regional food marketing); and

- The creation of a centralized porta $1^{15}$ for local food data and information about federally funded local food investments in alignment with the Administration's emphasis on data transparency.
While nearly all USDA agencies participated in the KYF2 task force to some degree, AMS's longstanding involvement in local food research and technical assistance, as well as Dr. Merrigan's deep knowledge of AMS programs from her prior stint as AMS administrator, virtually ensured that AMS had an important place on the KYF2 table. ${ }^{16}$ AMS Marketing Services's contributions to local food research literature during this time, aided and abetted by the interagency networks forged through KYF2, had three major foci, reflecting AMS's comparative expertise in local food market infrastructure/supply chain management and the collection and reporting of public-facing industry data:

- Developing more substantive analysis and technical guidance for the maturing farmers market industry, exemplified by the release of Supplemental Nutrition Assistance Program at Farmers Markets: A How-To Handbook $k^{17}$ in June 2010, co-authored by AMS Marketing Services, FNS, and the nonprofit Project for Public Spaces;

- Pioneering research in local/regional food aggregation to help smaller-scale producers access wholesale marketing channels, exemplified by the 2012 release of Moving Food Along the Value Chain: Innovations in Regional Food Distribution ${ }^{18}$ and the Regional Food Hub Resource Guide ${ }^{19}$; and

- Deploying technology to improve data transparency and public awareness and patronage of our farmers market directory database. These developments included the launch of a Foursquare farmers market "check-in" promotion with CNN's Eatocracy website (Gould, 2016), and the integration of geographic coordinates and mapping functions into the National Farmers Market Directory in late

\footnotetext{
${ }^{13}$ https://www.ers.usda.gov/webdocs/publications/46405/7028 err99 reportsummary 1 .pdf?v $=41056$

14 https://www.ers.usda.gov/webdocs/publications/46393/7054 err97 1 .pdf?v $=0$

15 https://www.ams.usda.gov/local-food-sector/compass-map

${ }^{16}$ I served as the first presenter at the "soft launch" of the KYF2 task force in May 2009, sharing my program's knowledge to date about the pros and cons of farm-to-school marketing from a producer perspective.

${ }^{17}$ https://www.mass.gov/files/documents/2016/08/vh/usda-howto-fm-ebt.pdf

${ }^{18}$ https://www.ams.usda.gov/sites/default/files/media/MovingFoodAlongValueChain.pdf

${ }^{19}$ https://www.ams.usda.gov/sites/default/files/media/Regional $\% 20$ Food $\% 20 H u b \% 20$ Resource $\% 20$ Guide.pdf
} 
2010, which allowed computer programmers to use the integrated dataset to support their own application programming interface (API) spinoffs. In 2013, USDA also used data from the National Farmers Market Directory to support its first federally developed API (Stanziani, 2013) as part of the Obama Administration's Digital Government Strategy to improve data transparency and public access to government data (Sinai \& Van Dyck, 2013).

\section{Building on Established Foundations, 2014-2016}

This time period was characterized by an expansion of existing local food grant authorities, the creation of new, dedicated funding streams for farmers market purchases, and an emerging interest in gauging the economic impact of local food investments. This reflected both the increased availability of data on the local food marketing environment and a growing interest among community and regional planners and economic development officials in considering food and agriculture as a critical element of their strategies.

Major developments included:

\section{- Augmentation of existing local food} grant authorities and creation of new dedicated funding streams. The 2014 farm bill created the Local Food Promotion Program (LFPP) in FY 2014 to complement the existing work of FMPP, authorizing US $\$ 30$ million in annual funding to support the administration of both grant programs. In addition, FY 2014 saw the launch of the Food Insecurity Nutrition Incentives (FINI) program within USDA's Food and Nutrition Service, which aimed to increase fruit and vegetable purchases by low-income recipients of SNAP benefits by providing incentives at the point of purchase;
- Creation of three additional national local food directories ${ }^{20}$ by AMS Marketing Services in 2014, signaling the program's growing interest in tracking industry practices and trends beyond farmers markets;

- The launch of new price reports ${ }^{21}$ by AMS Market News that publish price data for key locally grown and raised, organic, or sustainably grown and raised food products sold through a variety of direct-toconsumer, wholesale, institutional, and retail outlets. This includes direct-toconsumer sales of meat cuts from grass-fed and pasture-fed animals, and selected produce, meat, seafood, dairy items, and eggs at farmers markets, auction markets, farmto-school transactions and retail outlets across the country;

- The decision by NASS to carry out the $\mathbf{2 0 1 5}$ National Local Food Marketing Practices survey, ${ }^{22}$ published in December 2016, which provided unprecedented coverage and delineation of sales of food identified as locally grown and raised and was marketed through both direct and intermediated channels to wholesale buyers; and

- Publication in March 2016 of The Economics of Local Food Systems: A Toolkit to Guide Community Discussions, Assessments and Choices ${ }^{23}$ (referred to as the Toolkit), which was sponsored by AMS to help community stakeholders evaluate the economic impact of investing in local and regional food systems more reliably by introducing them to relevant case studies, best practices, and useful resources. The toolkit was subsequently embraced by thousands of practitioners across the country as a vital resource in guiding their community assessment process. Through the collective efforts of the report's dozen contributing authors, reviewers, and other organizational

\footnotetext{
20 https://www.ams.usda.gov/services/local-regional/food-directories

${ }^{21}$ https://www.ams.usda.gov/market-news/local-regional-food

22 https://www.nass.usda.gov/Surveys/Guide to NASS Surveys/Local Food/

${ }^{23}$ https://www.ams.usda.gov/publications/content/economics-local-food-systems-toolkit-guide-community-discussions-assessments
} 
partners, more than 20 national and regional training workshops and webinars were offered between 2016 and 2018. Financial support for these resources came primarily from AMS, including several that targeted underserved populations to help local planners, policy-makers, and interested residents better prepare to undertake various aspects of this assessment work in their own communities.

\section{Taking Stock and Spreading the Word, 2017-Present}

During the past couple of years, AMS Marketing Services has plunged further into reviewing the current "state of play" in local food research and sharing these observations with senior leadership, industry participants, market observers, and other community stakeholders. Given the massive accumulation of research, data, and performance reports that had occurred since the passage of the 2008 farm bill-including the results of 980 funded grants in the case of the Farmers Market Promotion Program alone-it seemed an appropriate time to assess what lessons had been learned from recent research and technical assistance in the local/regional food sector, examine ongoing barriers to success, and identify which steps should be taken to make our grant, research, and technical assistance programs more effective in reaching desired goals. This body of activity has consisted of three primary components:

- Publication of formal progress reports and peer-reviewed journal articles, which included the development and release of the 10-year progress report for the Farmers Market Promotion Program (USDA Agricultural Marketing Services, 2017) and an article by AMS Marketing Service personnel entitled "The Impacts of the Farmers Market and Local Food Promotion Programs" in the journal Community Development (O’Hara \& Coleman, 2017).

- Organization of national conferences to share research results and learnings from project implementation, which included AMS's organization and sponsorship of the
Local Food Impact Summit in April 2017

and the National Direct Agricultural

Marketing Summit in September 2018. A

follow-up summit will take place in

Rosemont, Illinois, October 7-9, 2019.

- Establishment of cooperative research agreements with land-grant institutions to undertake formal evaluations of AMS grant programs (or subsets of these programs) to:

- Better understand and categorize the types of outcomes that are being achieved as a result of federal investments;

- Consider the adequacy and reliability of current metrics and reporting requirements in capturing the full dimension of progress achieved; and

- Gain greater insights about the types of interventions that seem to lead to the most profitable or beneficial outcomes.

To this end, AMS grant and marketing program managers have established cooperative research agreements with evaluation and subject matter experts at Auburn University, Kansas State University, and Oregon State University within the past couple of years to carry out extensive impact assessments of the agency's competitively awarded grants programs (specifically, the Federal-State Marketing Improvement Program, the Farmers Market and Local Food Promotion Program, and the subset of AMS grants provided to facilitate local and regional meat processing activities).

Other areas of inquiry that are ripe for development - and are beginning to attract the attention of USDA career staff-involve an attempt to streamline and achieve greater alignment in measurements and reporting requirements across multiple grant programs, at least in key areas of overlapping interest. For example, the USDA coordinator for local and regional food issues, housed within AMS, has created a departmentwide working group to examine opportunities for consolidating grant program objectives and data-gathering requirements across program and agency lines. The combination of these activities, which aim to better identify key indicators of impact and design reporting requirements that match the capacity of 
grant recipients to provide accurate data to a greater extent, can be expected to:

- Foster more accurate reporting by project cooperators, which would yield better data integrity and, over the longer term, more accurate evaluation of program effectiveness;

- Allow for easier quantification of the aggregate impact of multiple federal grant programs on core measures of progress; and

- Help USDA- and interested stakeholders-better understand the levers and influences that exert the greatest contribution to successful grant outcomes.

\section{What Are We Learning?}

One of the major lessons that emerged during recent conference discussions was the realization that emerging analysis of newly available datasets may change our perceptions about the relative economic competitiveness and impact of local/ regional food businesses. For example, an analysis of the most recently available Census of Agriculture data by USDA's Economic Research Service indicated that the survival rate for farms participating in direct-to-consumer markets was greater than the survival rate of other farms. Other research studies by land-grant universities, as illustrated on the localfoodeconomics.com website funded by AMS and NIFA and managed by Colorado State University, indicate that suppliers to local/regional food markets may have a disproportionately positive impact on local job creation and economic multiplier effects compared to other food suppliers, based on their relatively high dependence on labor and levels of indirect and induced spending.

Furthermore, we also learned that we need to strengthen and increase the frequency of our communication with community stakeholders by:

- Promptly sharing data analysis with survey respondents to lessen survey fatigue and suspicion, develop trust, and ensure that respondents can make practical use of the results;

- Engaging with community stakeholders about appropriate indicators of success rather than making assumptions about what these indicators should look like. Following this protocol may require agencies to modify their current metrics; however, this will likely result in greater buy-in and responsiveness among the organizations being asked to report data. For example, in addition to asking how many jobs are created in a particular service area, agencies (based on feedback we received from conference attendees) may also want to ask how much these new employees are being paid; and

- Striving to understand the community capital formation aspects of local/ regional food system development rather than focusing on financial returns alone. Such measurements could attempt to capture such social, human, and intellectual capital dynamics as workforce preparation, skill development and mastery, attainment of relevant credentials and certifications, changes in awareness and behavior, organizational capacity, and development of supply chain networks. New methods of inquiry, such as social network analysis, can also help us obtain greater clarity on how well we are meeting this goal by giving us tools to measure such progress on a quantitative basis.

Our growing understanding of the important role of community engagement has also led AMS Marketing Services to embrace new opportunities for direct community intervention. With the encouragement of senior leadership, under both the Obama and Trump administrations, AMS Marketing Services was able to increase its financial and technical support of the Local Food, Local Places (LFLP) interagency initiative ${ }^{24}$ housed within the U.S. Environmental Protection Agency. Managed by a task force comprising representatives from EPA's Office of Community

24 https://www.epa.gov/smartgrowth/local-foods-local-places 
Revitalization, USDA's Agricultural Marketing Service and Rural Development agencies, the Centers for Disease Control and Prevention, the Delta Regional Authority (DRA) and, as of 2018, the Northern Border Regional Commission, the LFLP initiative supports locally led, community driven efforts to protect air and water quality, preserve open space and farmland, boost economic opportunities for local farmers and businesses, improve access to fresh local food, and promote childhood wellness. This support is provided through competitively awarded technical assistance workshops that take place at a site chosen by the applicant, where federal subject matter experts, community stakeholders and, often, professional facilitators meet for two days to jumpstart the development of a community's local food system action plan. Preliminary and follow-up conference calls with members of the community's core organizing team help ensure that the targeted community is prepared to take full advantage of available technical assistance, both during the intensive on-site workshop and through extended connections with federal service providers. In selecting deserving communities, special consideration is given to lower-capacity communities that are in the early stages of developing local food enterprises.

At the request of senior agency leadership, AMS Marketing Services staff began its involvement with the LFLP task force in the spring of 2015, quickly recognizing that they could make an important contribution to the success of these workshops by offering expertise and insights on farm market operations and practices, food facility design and management, and local food aggregation/supply chain logistics. Since that time, AMS Marketing Services has become a linchpin of the initiative by providing funding to sustain its operation since 2016, helping to organize and participating in the majority of technical assistance workshops offered per year, serving as reviewers of submitted applications, and sharing responsibility for facilitating workshops and delivering presentations alongside EPA personnel and external contractors in locations where their subject matter expertise is most relevant. In fact, the emergent leadership of AMS Marketing Services has enabled EPA to reduce its dependence on professional facilitation, allowing the agency to extend its limited funding resources to a wider range of eligible communities. Between 2015 and 2018, LFLP awarded and implemented 93 workshops, ranging between 16 and 27 per year based on the level of partner agency contributions and opportunities for substituting agency personnel for hired external facilitators.

\section{Parting Thoughts}

While the path has not always been straightforward, USDA, and most notably AMS, have unquestionably played a key role in elevating the national discussion about local food systems and accelerating the move toward developing a robust body of related data, research, and practical resources. This has been accomplished through a variety of techniques, such as collecting and reporting data that unveil the structure of the local food system on an increasingly granular level, documenting best practices and business models associated with marketing success, and disseminating lessons learned through a variety of channels (e.g., reports, conferences, webinars, in-person trainings) so that practitioners and market observers can make effective use of the information. To USDA's credit, these initiatives have often included the participation of multiple federal agencies, allowing these initiatives to benefit from a broad array of interdisciplinary perspectives and provide insights designed to meet the specific needs of targeted stakeholder groups. In addition, AMS's support of work that facilitates the adoption of reliable and compatible economic impact assessment methods, such as the Toolkit and the agency's call for papers for the special issue of JAFSCD, have helped build the economic argument for local food investments and made gathering economic evidence more accessible to planners and community stakeholders.

One way of gauging just how far USDA has come in advancing key local food research objectives is by reviewing some of the aspirational goals mentioned by attendees of the first National Farmers Market Summit in 2007 and noting how many of them have been at least partially addressed in the ensuing 10 years with the help of USDA involvement or support. Posted below is the list of "recommended strategies" for research mentioned 
by attendees of the 2007 Summit. From this entire list, the goals that have been met or partially fulfilled appear in bold type, with examples of relevant accomplishments in the footnotes. As one can see, the vast majority of desired action steps mentioned in the Summit proceedings report have already been addressed by USDA to some degree:

- Establishment of an open-source, online site to share pertinent resources and facilitate more effective communication among farmers market vendors, managers, community development practitioners, researchers, funders, and other stakeholders. ${ }^{25}$

- Research institutes should play a key role in setting up accessible, user-friendly online clearinghouses of farmers market data, tools, and best practices, as well as providing farmers market advocates with the kind of information needed to push for policy and regulatory reform. ${ }^{26}$

- Documenting successful farmers markets, particularly farmers markets serving low-income areas. ${ }^{27}$

- Collecting local, regional, and national data on consumer and market trends. ${ }^{28}$

- Conducting studies of the effectiveness of farmers market advertising and promotion.

- Adding new direct marketing questions to the USDA NASS Census of Agriculture. ${ }^{29}$

- Assessments of the economic impacts of farmers markets on vendors and community. ${ }^{30}$

- Conducting applied research and developing practical tools, such as business management programs and professional development training programs.

- Guidance related to infrastructural and operational improvements at farmers markets. $^{31}$

- Providing consistent information about the use of new technologies, such as electronic benefits transfer (EBT), to enhance access to farmers markets (USDA Agricultural Marketing Services, USDA Food and Nutrition Service, \& Project for Public Spaces, 2010).

- Seeking partnerships with nontraditional organizations who may share mutual areas of interest related to farmers markets, local foods, sustainable agriculture, and community food security, such as the U.S. Environmental Protection Agency, the U.S. Department of Health and Human Services, military branches, the National Science Foundation, and various community-based organizations that may

\footnotetext{
${ }^{25}$ Such as the AMS-supported, CSU-hosted https://www.localfoodeconomics.com website platform and listserv, and the eXtension interest group Community, Local and Regional Food Systems 
not typically work in the agricultural arena. ${ }^{32}$

- Better document the economic, social, environmental, and health benefits of farmers markets through research and analysis. ${ }^{33}$

- Develop science-based theories, practices, and procedures about farmers markets, derived from empirical observations, tests, experiments, and measurable evidence that:

- Convey practical information to vendors and market managers, ${ }^{34}$ and

- Are accessible, user-friendly concepts that can be used to persuade decisionmakers about farmers market policies..$^{35}$
Nevertheless, much work remains in plumbing the depths of local food systems analysis, even from the narrow perspective of understanding potential producer benefits from local food market transactions. NASS has only very recently begun to capture and report data at a granular-enough level to allow for a more holistic understanding of the local food supply chain in both direct-to-consumer and intermediated marketing channels, even though the latter currently accounts for a growing (and significant majority) share of local food sales. ${ }^{36}$ For example, the release of the 2017 Census of Agriculture in April 2019 marked the first time that a census of agriculture has featured data delineating the value of locally or regionally branded farm products sold for human consumption

\footnotetext{
${ }^{32}$ Includes USDA's collaboration with the Federal Reserve on Harvesting Opportunity: The Powver of Regional Food System Investments to Transform Communities (August 2017; see https://www.stlouisfed.org/community-development/publications/harvesting-opportunity) and the November 2015 AMS report on Farmers Markets at Military Installations, developed in partnership with the U.S. Department of Defense (see https://www.ams.usda.gov/publications/content/guide-farmers-markets-military-installations).

${ }^{33}$ USDA has carried out quite a bit of work to date on the economic benefit question. Key products include the 2015 NASS Local Food Marketing Practices survey and the 2017 Census of Agriculture, which provide data specific to marketing channels on direct to consumer sales of farm products. Additional examples include AMS's analysis of farmers market performance indicators and economic multipliers mentioned in footnote 30. A memorandum of understanding is also underway between AMS and NASS to support the next national survey of farmers market managers in 2020, which can be expected to yield additional information on market performance and its relationship to specific market practice. On the other benefit questions_-social, environmental, healthI would submit that the assessment of market benefits by USDA has been less comprehensive, although extensive resources have been devoted to creating information portals and facilitating research on social and environmental barriers to obtaining fresh food, including the use and patronage of farmers markets. These include development of the ERS Food Access Research Atlas (see https://www.ers.usda.gov/data-products/food-access-research-atlas/); the ERS Food Environment Atlas (see https://www.ers.usda.gov/data-products/food-environment-atlas/); sponsorship by FNS of three national research projects on nutrition assistance at farmers markets (Understanding Current Operations [see https://fns-prod.azureedge.net/sites/default/files/FarmersMarketsOps.pdf]; Understanding Shopping Patterns (see https://www.fns.usda.gov/snap/nutrition-assistance-farmers-markets-understanding-shopping-patterns-snap-participants), and the Farmers Market Incentive Provider Study (see https:// fns-prod.azureedge.net/sites/default/files/FarmersMarketIncentiveProvider.pdf); and the administration by FNS of Farmers Market Support Grants (see https://www.fns.usda.gov/pressrelease/2016/fns-001316) and the Gus Schumacher Nutrition Incentive Program (formerly known as the Food Insecurity Nutrition Incentive Program; see https://nifa.usda.gov/sites/default/files/rfa/20190423-fy-2019-gus-schumacher-incentive-program-rfa.pdf). 34 A preliminary example of such work is the AMS report Results of Dot Survey, USDA Outdoor Farmers Market Washington, DC, (September 2011; https://www.ams.usda.gov/publications/content/results-dot-survey-usda-outdoor-farmers-market-washington-dc). Presentations on sharing lessons learned from market data collection efforts made up a significant portion of the training material at the 2018 National Direct Marketing Summit and continue to feature prominently in the latest 2019 round of AMS technical assistance offered by the FMPP/LFPP program to farmers market managers and other farmers market personnel.

${ }^{35}$ While not strictly farmers market-related, the benchmark section of the www.localfoodeconomics.com website, funded by AMS Marketing Services and maintained by Colorado State University, provides an early window into understanding the differences between local food farms and other farms in terms of structure and economic impact.

36 According to the 2017 Census of Agriculture, sales of locally branded or marketed food through wholesale or intermediated channels in 2017 exceeded US $\$ 9$ billion, compared to less than US $\$ 3$ billion in local food sold through direct to consumer channels. The 2015 NASS Local Food Marketing Practices survey (https://www.nass.usda.gov/Surveys/Guide to NASS Surveys/Local Food/index.php) represented the first-ever survey conducted by USDA's National Agricultural Statistics Service to produce benchmark data about local food marketing practices delineated by marketing channel (e.g., farmers markets, CSAs, restaurants, roadside stands, food hubs).
} 
through wholesale or intermediated marketing channels. ${ }^{37}$ It was also the first census of agriculture to incorporate value-added products into the total sales volume of locally or regionally marketed food. This means that, although it likely provides a more accurate measure of local food sales volumes on a national level than we have seen to date, it still remains imperfect, as non-edible farm products commonly sold at farmers markets and roadside stands, such as ornamental crops, are still excluded from the measure. So even from the basic level of sector trend and impact analysis alone, there seems to remain considerable room for improvement and additional refinement.

The other area of food systems that merits further analysis is the rapid evolution of delivery and distribution system for local food. With the growing popularity of hybrid business models that transcend traditional local food system silos (e.g., subscription agriculture or CSA models that use farmers markets as recruitment and delivery points), it becomes even more imperative that future research activities capture data elements that allow research to understand the potential implications of such future shifts and synergies in market practice on firm and producer profitability to a greater degree. As members of Millennial and Generation Z come of age and increase their relative purchasing power, undoubtedly they will exert even greater influence on local food demand than they already presently do. This suggests that the time may be ripe for conducting more comprehensive analyses that seek to connect generational behavior patterns (e.g., time devoted to cooking at home, desire for convenience, interest in nutrition and product transparency, perceived value) to local food purchasing habits and store format choices. Lastly, the "last mile" distribution question remains a difficult nut to crack, resulting, as we have seen, in the consolidation, acquisition, and, occasionally, closing of various firms that have attempted to provide home delivery of local foods. ${ }^{38}$ It may be time for a fresh look at how local food hubs might be able to better leverage their transportation and distribution functions in partnership with other hubs or in partnership with traditional wholesale operators and distributors.

\section{My Personal Postscript, Or Life Beyond the USDA Gates}

Before leaving the USDA at the end of January 2019, I was frankly too busy to think much about my potential future contributions to the local food sector, even though one of my motivations for leaving was the hope that it would free me up to become more involved in community development activities. However, over the past few years, largely as a result of working on the economic impact assessment Toolkit on local food systems and the LFLP initiative, I found myself gravitating toward work that involved a community development dimension, where I could share my knowledge of local food market business models and federal programs with a grassroots audience in order to help them achieve their desired development goals.

In partial preparation for my eventual retirement from USDA, I pursued an open position on my local (Montgomery County, Maryland) food policy council three years ago, and while my application did not lead to my appointment on the council, I ended up being invited to join the its food economy working group, which has proven to be an excellent fit for my knowledge and talents. Very recently I was nominated by the county office of agriculture and appointed by the Montgomery County Council to serve a limited-term appointment as a nonfarmer representative on the county's agricultural advisory committee, which serves as a liaison between county government and the agricultural sector, coordinates the provision of local government services in rural areas of the county, and provides input and recommendations on rural

\footnotetext{
${ }^{37}$ The 2015 Local Food Marketing Practices Survey, published in December 2016, used a somewhat similar framework for capturing and presenting data based on a nationally representative sample of approximately 44,000 respondents.

${ }^{38}$ Examples include the merger and eventual closure of Relay Foods and Door to Door Organics (see https://www.dailyprogress. $\mathrm{com} /$ news/local/door-to-door-organics-closes-a-year-after-acquiring-relay/article ba90b4de-ce46-11e7-b337-f328459d1fb0.html), and the consolidation of Good Eggs (see https://www.fastcompany.com/40554143/how-good-eggs-came-back-from-the-brink-andplans-take-on-amazon).
} 
and agricultural issues.

To my surprise and delight, I have received great encouragement from many corners of the local food world since announcing my retirement at the end of January 2019, renewing my connections with old friends and colleagues and making new friends along the way. In this vein, I need to give special recognition to Rose Hayden-Smith and Angie Tagtow, who very generously invited me (at a reduced registration rate) to attend the November 2018 meeting of the Kellogg Foundation Leadership Alliance, where I found great fellowship, encouragement for following my career instincts, and guidance on next step strategies. I was also fortunate enough to receive an invitation to keynote the Northeast Indiana Local Food Network's annual forum in Ft. Wayne, Indiana, in March 2019, thanks to an endorsement by local community advocate (and former National Sustainable Agriculture Coalition grassroots intern) Stephanie Henry and with support from Northeast Indiana Local Food Network Executive Director Janet Katz.

Through the networking opportunities offered by the forum and other local food-related gatherings in the D.C. area, I have continued to provide technical guidance to a wide variety of local food system stakeholders on issues ranging from food hub logistics and the federal grant application process to the economic and food system contributions of urban agriculture. I am particularly proud of the fact that I am involved in two activities that seek to boost food system resilience through regional approaches. These include being part of a task force working to enhance the visibility and capacity of the Midwest Sustainable Agriculture Working Group (Midwest SAWG), ${ }^{39}$ so that it can assume a role similar to those currently occupied by the Southern and Northeast SAWGs. I am an invited contributor to the food distribution section of a planned update of Northeast SAWG's It Takes a Region report. ${ }^{40}$ Meanwhile, with the encouragement of NSAC's Wes King and Juli Obudzinski, I submitted an application in March to be considered for an appointment to the NASS Advisory Committee on Agriculture Statistics, so time will tell whether I will have the chance to exert any future influence on national policy as well. Given the relatively short amount of time I've been "retired," my thoughts about where best to focus my attention continue to evolve, but I firmly believe that I will continue to be a presence in the local food scene for some time to come, even if it's in a somewhat different capacity.

\section{References}

Diamond, A., \& Soto, R. (2009). Facts on Direct-to-consumer Food Marketing: Incorporating Data from the 2007 Census of Agriculture. Washington, D.C.: U.S. Department of Agriculture, Agricultural Marketing Service. https://doi.org/10.9752/MS035.05-2009

Gould, D. (2016, August 07). CNN \& Foursquare collaborate to promote healthy eating. Retrieved from https://foodtechconnect.com/2010/09/29/cnn-foursquare-collaborate-to-promote-healthy-eating/

O’Hara, J. K., \& Coleman, C. (2017). The Impacts of the Farmers Market and Local Food Promotion programs. Community Development, 48(5), 681-696. https://doi.org/10.1080/15575330.2017.1350729

Organic Trade Association \& GRO Organic Core Committee. (2015). RevP Program Application Industry Overview [Application to USDA AMS Research and Promotion Program]. Retrieved from https://www.ams.usda.gov/sites/default/files/media/OTAOrganicCheckoffApplicationUSDA Combined.pdf

Payne, T. (2002). U.S. farmers' markets 2000: A study of emerging trends. Journal of Food Distribution Research, 33(1), 173175. Retrieved from https://ageconsearch.umn.edu/record/27625/ files/33010173.pdf

Pirog, R. S., Van Pelt, T., Enshayan, K., \& Cook, E. (2001). Food, fuel, and freeways: An Iowa Perspective on how Far Food Travels, Fuel Usage, and Greenhouse Gas Emissions. Ames, Iowa: Leopold Center for Sustainable Agriculture. Retrieved from https://lib.dr.iastate.edu/leopold pubspapers/3

\footnotetext{
${ }^{39}$ https://www.midwestsawg.com/

${ }^{40}$ https://api.ning.com/files/nRTEesYytUshUdiU-IEPLW61FFE3Zgcz44LFacsKlo5K6P0X43KSuSZOkwFHiTQF6a0t5O9mAXu WNb0HbP7GZigKVUkE7gVY/NESAWGRegionalFoodSystemFINALSept2010.pdf
} 
Ragland, E., \& Tropp, D. (2009, May). USD A national farmers market manager survey, 2006. Washington, D.C.: U.S. Department of Agriculture. https://doi.org/10.9752/MS037.05-2009

Robyn Van En Center Staff. (2009, April 16). 2007 Census of Agriculture Results. Retrieved from https://csacenter.blogspot.com/2009/04/2007-census-of-agriculture-results.html

Siebert, J. W., Nayga, R. M., \& Thelen, G. C. (2000, March). Enhancing the financial and marketing performance of firms in the smoked and processed meat industry. Journal of Food Distribution Research, 31(1), 1-6.

Sinai, N., \& Van Dyck, H. (2013, May 23). Agency spotlight: Making mobile government a reality [Blog post]. Retrieved from the archive site of the Obama Administration White House: https://obamawhitehouse.archives.gov/blog/2013/05/23/agency-spotlight-making-mobile-government-reality

Stanziani, P. (2013, May 15). USDA announces new API for the National Farmers Market Directory. Retrieved from https://www.ams.usda.gov/press-release/usda-announces-new-api-national-farmers-market-directory

Tropp, D., \& Barham, J. (2008, March). National Farmers Market summit proceedings report. Washington, D.C.: U.S. Department of Agriculture, Agricultural Marketing Service. https://doi.org/10.9752/MS030.03-2008

Tropp, D., \& Olowolayemo, S. (2000, December). How Local Farmers and School Food Service Buyers Are Building Alliances: Lessons Learned from the USDA Small Farm/School Meals Workshop, May 1, 2000. Retrieved from the U.S. Department of Agriculture, National Agricultural Library website: https://naldc.nal.usda.gov/download/38355/PDF

Tropp, D., Siebert J. W., Nayga R. M., Thelen, G., \& Kim, S. Y. (2004, March). Enhancing Commercial Food Service Sales by Small Meat Processing Firms. Retrieved from the U.S. Department of Agriculture, Agricultural Marketing Service website: https://naldc.nal.usda.gov/download/38382/PDF

U.S. Department of Agriculture, Agricultural Marketing Service [USDA AMS]. (2017, January). Farmers Market Promotion Program: 2016 report. Retrieved from https://www.ams.usda.gov/sites/default/files/media/FMPP2016Report.pdf

USDA AMS, Marketing Services Division. (n.d.). National count of farmers market directory listings, 1994-2019 [Chart]. https://www.ams.usda.gov/services/local-regional/farmers-markets-and-direct-consumer-marketing

USDA AMS, USDA Food and Nutrition Service, \& Project for Public Spaces, Inc. (2010, June). Supplemental Nutrition Assistance Program (SNAP) at Farmers Markets: A How-to Handbook. Retrieved from https://www.mass.gov/files/documents/2016/08/vh/usda-howto-fm-ebt.pdf

USDA, National Agricultural Statistics Services [USDA NASS]. (2007, November). 2007 Census of Agriculture report form guide. Retrieved from https://www.nass.usda.gov/AgCensus/Report_Form_and_Instructions/2007_Report_Form/2007_RFG.pdf

USDA Office of Communications. (n.d.). Factsheet: The four pillars of agriculture and rural economic development [Press release]. Retrieved from https://www.usda.gov/media/press-releases/2015/05/20/may-20-2015-secretary-vilsack-spokedelegations-34-countries-part 